J. Am. Chem. Soc. Supplementary Information

\title{
A Chemical Approach to the Pharmaceutical Optimization of an Anti-HIV Protein
}

Les P. Miranda*,†, Haiyan Shaoł, Jason Williams, Shiah-Yun Chen, Ting Kong, Rod Garcia, Yvonne Chinn, Nathalie Fraud, Bill O’Dwyer, Jay Ye, Jill Wilken, Donald E. Low, E. Neil Cagle, Maia Carnevali\#, Alexander Lee, Di Song, Ada Kung, James A. Bradburne, Xavier Paliard^, and Gerd G. Kochendoerfer§

Gryphon Therapeutics, 600 Gateway Boulevard, South San Francisco, CA 94080 USA

*To whom correspondence should be addressed. Email: lesm@amgen.com

This PDF file includes:

Structure of N-terminus of PSC RANTES

Structure of the $16 \mathrm{kDa}$ branched polymer ${ }^{2}$ used in analogs $\mathbf{1}$ to $\mathbf{6}$

References 
Figure S1: Structure of N-terminus of PSC RANTES ${ }^{1}$

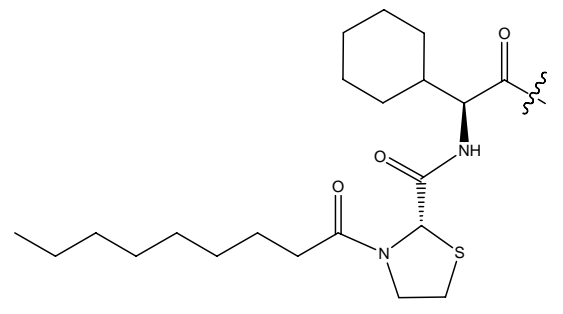

Figure S2: Structure of the $16 \mathrm{kDa}$ branched polymer ${ }^{2}$ used in analogs 1 to $\mathbf{6}$

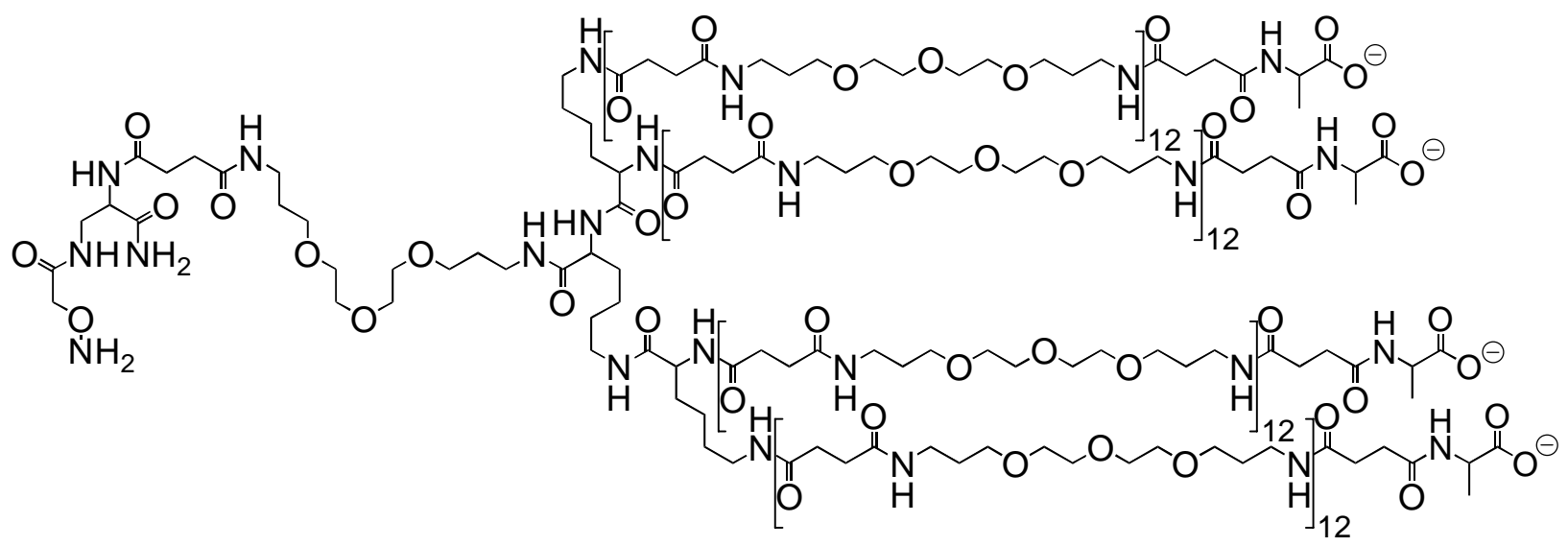

\section{Supplementary References:}

1. Hartley, O.; Gaertner, H.; Wilken, J.; Thompson, D.; Fish, R.; Ramos, A.; Pastore, C.; Dufour, B.; Cerini, F.; Melotti, A.; Heveker, N.; Picard, L.; Alizon, M.; Mosier, D.; Kent, S.; Offord, R., Proc. Natl. Acad. Sci. USA 2004, 101, (47), 16460-16465.

2. Kochendoerfer, G. G. et al., Science 2003, 299, 884-887. 